\title{
Particle Accelerator
}

National Cancer Institute

\section{Source}

National Cancer Institute. Particle Accelerator. NCI Thesaurus. Code C94854.

An instrument that uses electric fields to propel charged particles to high speeds and energies. 